\title{
Synthesis of Cesium Lead Halide Perovskite Nanocrystals in a Droplet-Based Microfluidic Platform: Fast Parametric Space Mapping
}

Ioannis Lignos, ${ }^{\dagger}$ Stavros Stavrakis, ${ }^{\dagger}$ Georgian Nedelcu, ${ }^{\ddagger}, \S$ Loredana Protesescu, ${ }^{\ddagger}, \S$ Andrew J. deMello, ${ }^{*}, \dagger$ and Maksym V. Kovalenko*, $*, \S$

${ }^{\dagger}$ Institute for Chemical and Bioengineering and ${ }^{\ddagger}$ Institute of Inorganic Chemistry, Department of Chemistry and Applied Biosciences, ETH Zürich, Vladimir-Prelog-Weg 18093 Zürich, Switzerland

${ }^{\S}$ Empa-Swiss Federal Laboratories for Materials Science and Technology, Überlandstrasse 129, 8600, Dübendorf, Switzerland

\section{Supporting Information}

ABSTRACT: Prior to this work, fully inorganic nanocrystals of cesium lead halide perovskite $\left(\mathrm{CsPbX}_{3}, \mathrm{X}=\mathrm{Br}, \mathrm{I}, \mathrm{Cl}\right.$ and $\mathrm{Cl} / \mathrm{Br}$ and $\mathrm{Br} / \mathrm{I}$ mixed halide systems), exhibiting bright and tunable photoluminescence, have been synthesized using conventional batch (flask-based) reactions. Unfortunately, our understanding of the parameters governing the formation of these nanocrystals is still very limited due to extremely fast reaction kinetics and multiple variables involved in ion-metathesis-based synthesis of such multinary halide systems. Herein, we report the use of a

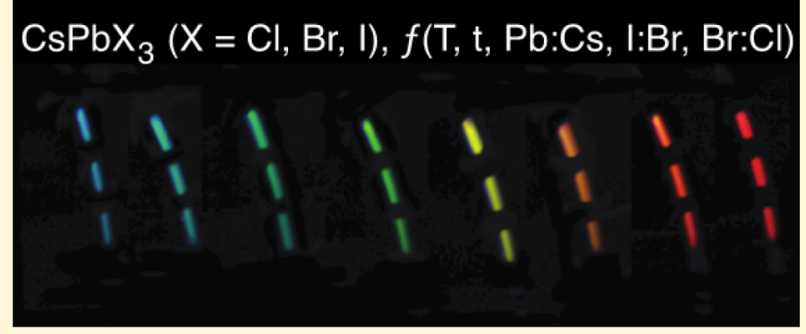
droplet-based microfluidic platform for the synthesis of $\mathrm{CsPbX}_{3}$ nanocrystals. The combination of online photoluminescence and absorption measurements and the fast mixing of reagents within such a platform allows the rigorous and rapid mapping of the reaction parameters, including molar ratios of $\mathrm{Cs}$, $\mathrm{Pb}$, and halide precursors, reaction temperatures, and reaction times. This translates into enormous savings in reagent usage and screening times when compared to analogous batch synthetic approaches. The early-stage insight into the mechanism of nucleation of metal halide nanocrystals suggests similarities with multinary metal chalcogenide systems, albeit with much faster reaction kinetics in the case of halides. Furthermore, we show that microfluidics-optimized synthesis parameters are also directly transferrable to the conventional flask-based reaction.

KEYWORDS: Perovskites, droplets, microfluidics, nanocrystals, quantum dots, halides

$\mathrm{I}$ $\mathrm{n}$ recent years, multiple reports have demonstrated the outstanding optoelectronic characteristics of lead halide semiconductors with perovskite crystal structures, primarily, hybrid organic-inorganic lead halide perovskites such as $\mathrm{CH}_{3} \mathrm{NH}_{3} \mathrm{PbX}_{3}(\mathrm{X}=\mathrm{Cl}, \mathrm{Br}$, or $\mathrm{I}$, or mixed $\mathrm{Cl} / \mathrm{Br}$ and $\mathrm{Br} / \mathrm{I}$ systems) in the form of thin films, microcrystals, and bulk single-crystals. $^{1-12}$ For instance, $\mathrm{CH}_{3} \mathrm{NH}_{3} \mathrm{PbX}_{3}$ perovskites have been used as inexpensive absorber layers in solar cells with certified power conversion efficiencies of up to $20 \%,{ }^{1-4,13-15}$ in highly sensitive solution-cast photodetectors operating in the visible, ${ }^{16,17}$ ultraviolet, ${ }^{18,19}$ and $\mathrm{X}$-ray ${ }^{20}$ regions of the electromagnetic spectrum, in light emitters ${ }^{21}$ and as optical gain media for lasing. ${ }^{15,22-25}$

Unsurprisingly, the outstanding photophysical characteristics of lead halide perovskites have motivated significant research into nanostructures, such as nanocrystals (NCs). Most efforts in the last two years have focused on supported and colloidal $\mathrm{CH}_{3} \mathrm{NH}_{3} \mathrm{PbX}_{3} \mathrm{NCs}^{26-37}$ In parallel, fully inorganic cesiumbased cuisines $\left(\mathrm{CsPbX}_{3}\right)$ have also received great attention since early $2015 .^{38-46}$ Very recently, facile one-pot colloidal syntheses based on ionic metatheses reactions in organic solvents have yielded colloidal $\mathrm{CsPbX}_{3} \mathrm{NCs}$ with strong emission, photoluminescence (PL) quantum yields (QYs) of up to $90 \%$ and narrow emission full width at half maxima (fwhm, 12-40 nm for PL peaks ranging from $410 \mathrm{~nm}$ for $\mathrm{CsPbCl}_{3}$ to $700 \mathrm{~nm}$ for $\left.\mathrm{CsPbI}_{3}\right) .{ }^{38}$ On the basis of these optical characteristics, $\mathrm{CsPbX}_{3} \mathrm{NCs}$ represent highly attractive alternatives to more traditional and toxic Cd-chalcogenide quantum dots (QDs, i.e. semiconductor NCs possessing sizedependent band gap energies). The facile anionic compositional tuning of $\mathrm{PL}$ properties with high precision $( \pm 1 \mathrm{~nm} !)$ from blue to red by forming $\mathrm{Cl} / \mathrm{Br}$ and $\mathrm{Br} / \mathrm{I}$ solid solutions is the major and inherent advantage of $\mathrm{CsPbX}_{3} \mathrm{NCs}$. Cd chalcogenides cannot be efficiently wavelength-tuned by adjusting their anionic composition but must be quantumsize-engineered via ultraprecise colloidal synthesis providing accurate control over the size and size-dispersion. For instance, $\mathrm{PL}$ tuning of CdSe NCs in the blue-green-orange region of the visible spectrum requires them to be extremely small $(\leq 5 \mathrm{~nm})$ and such NCs usually exhibit rather low PL QYs $(\leq 5 \%)$ due to midgap trap states. Bright and tunable emission from Cdchalcogenides is best achieved through complex size- and morphology-engineered nanoheterostructures, such as core-

Received: December 7, 2015

Revised: January 27, 2016

Published: February 2, 2016 
a

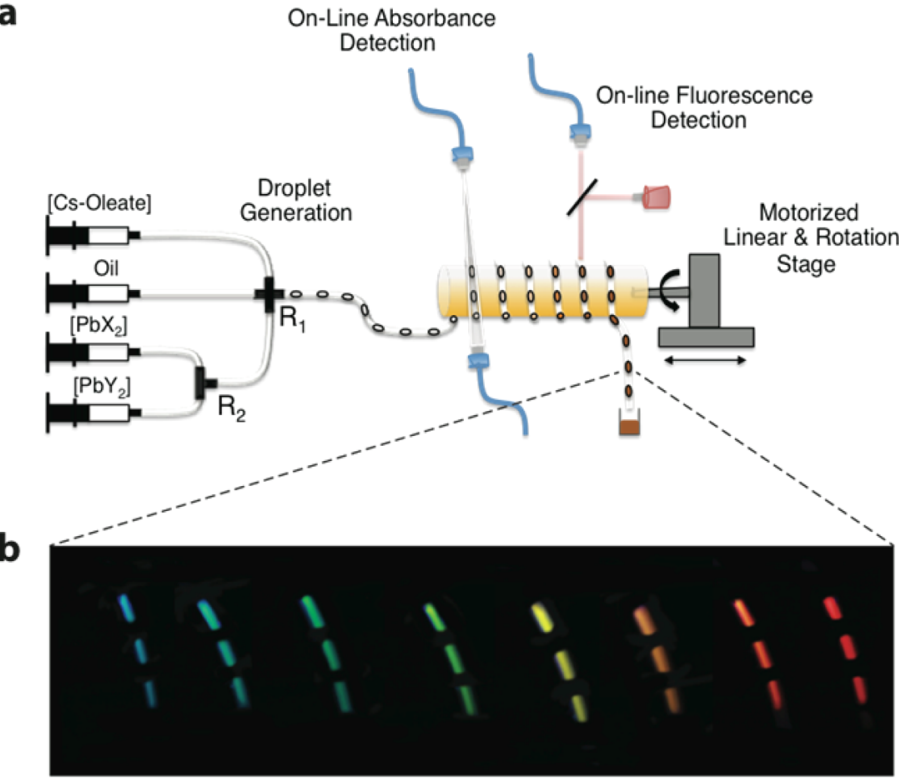

C

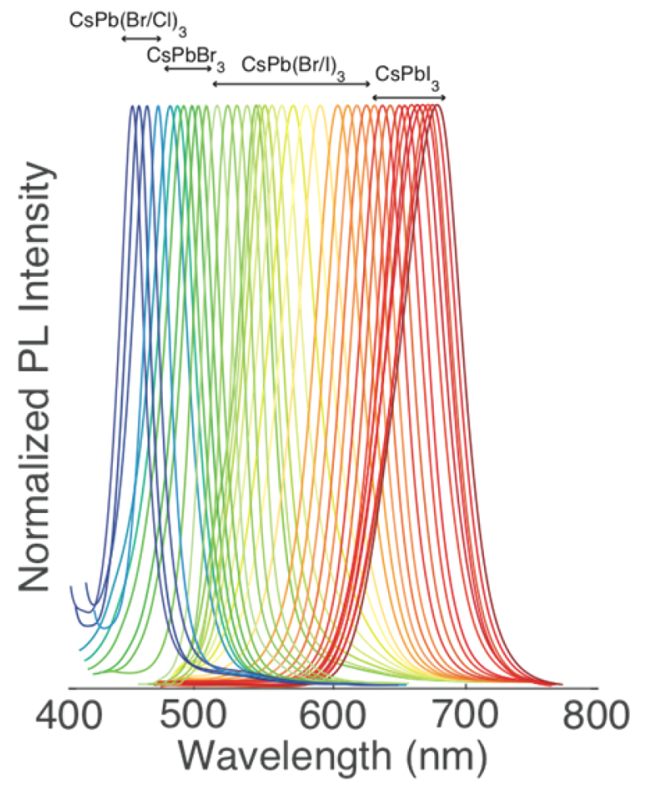

Figure 1. (a) Illustration of the droplet-based microfluidic platform integrated with online absorbance and fluorescence detection for the synthesis and real time characterization of $\mathrm{CsPb}_{3}$ perovskite NCs. We note that absorbance and fluorescence can be taken at the same location (as in this work) or, as drawn here for clarity, at different locations along the heating zone. The microfluidic platform allows for precise tuning of the chemical payload of the formed droplets by continuously varying the ratio between the lead and cesium sources $\left(R_{1}\right)$ and the ratio between halides $\left(R_{2}\right)$. Typical flow rates for the carrier phase were 10-500 and $0.1-350 \mu \mathrm{L} \mathrm{min}^{-1}$ for the dispersed phase. (b) Image of the generated droplets after exiting the heating zone taken under UV excitation $\left(\lambda_{\mathrm{ex}}=405 \mathrm{~nm}\right)$, showing bright PL of CsPbX $\mathrm{NCs}_{3}$ (c) Online fluorescence spectra of CsPbX $\mathrm{NCs}_{3}(\mathrm{X}$ : $\mathrm{Cl}, \mathrm{Br}, \mathrm{I}$ and $\mathrm{Cl} / \mathrm{Br}$ and $\mathrm{Br} / \mathrm{I}$ mixed halide systems) spanning the whole visible spectral region with narrow emission linewidths.
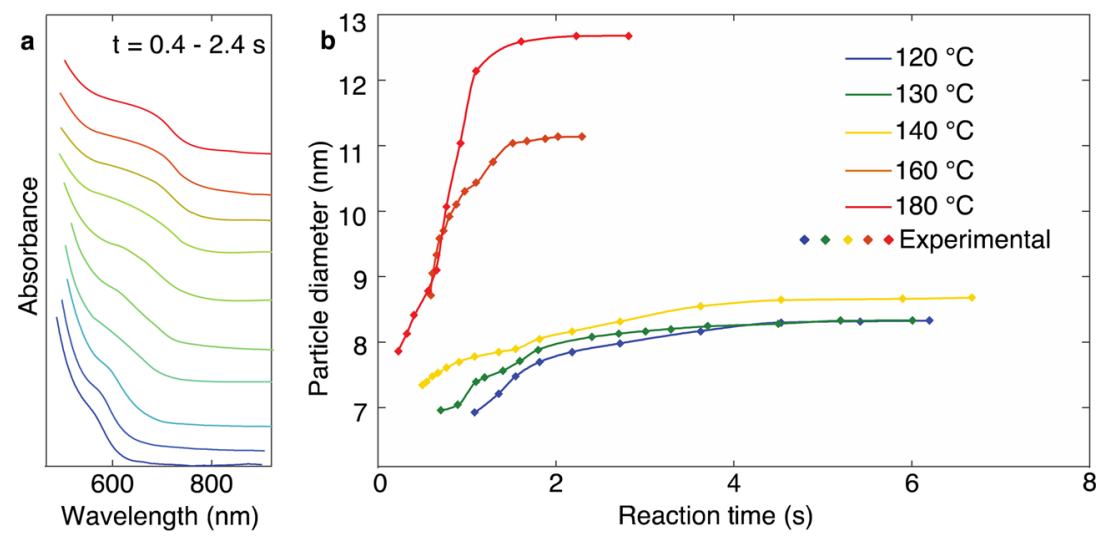

Figure 2. (a) Temporal evolution of online absorption spectra of $\mathrm{CsPbI}_{3} \mathrm{NCs}$ at $180{ }^{\circ} \mathrm{C}\left(R_{1}=7.8\right)$. (b) Variation of particle diameter as a function of reaction time while temperature remains constant $\left(120-180{ }^{\circ} \mathrm{C}\right)$.

shell morphologies, with independent control of the core and shell compositions and thicknesses (e.g., $\mathrm{CdSe}_{\text {core }} / \mathrm{ZnCdS}_{\text {shell }}$ or "giant-shell" CdSe $\left.\mathrm{core}_{\text {e }} / \mathrm{CdS}_{\text {shell }}\right)^{47-50}$ and anisotropic CdSe-CdS dot-in-rod and platelet-like morphologies. ${ }^{51,52}$ In these structures, wide-gap shell materials serve the purpose of efficient electronic surface passivation to ensure high PL QYs from CdSe regions. ${ }^{47-50}$ Herein lies the second key advantage of lead halide perovskites, the high tolerance of their band structure to structural defects, such as vacancies of atoms or, as in the case of NCs, surface dangling bonds. ${ }^{38,53}$ Hence the realization of high $\mathrm{PL}$ QYs does not require electronic passivation with wider-gap shells and thus greatly reduces the overall cost and complexity of the synthetic procedure. Furthermore, it should be noted that halides are less susceptible to photodegradation. The main challenge for lead halide NCs, however, relates to their small but finite solubility in water and polar solvents, which currently limits their biological application and restricts the list of solvents and non-solvents that can be used for isolation and dispersion of such NCs.

In this study, we sought to develop a better understanding of the kinetics and factors governing the formation of $\mathrm{CsPbX}_{3}$ NCs. Owing to the rather fast underlying ionic metathesis reaction, the nucleation and the growth of $\mathrm{CsPbX}_{3} \mathrm{NCs}$ occurs on unusually fast time scales (over a millisecond to several seconds time span), ${ }^{38}$ which contrasts with the slower and thus better controlled "molecular-like" elemental steps that occur during the nucleation of more covalently bonded metal chalcogenides or pnictides. Fast rates of formation of $\mathrm{CsPbX}_{3}$ NCs are comparable to (or faster than) the speed of homogeneous mixing of reagents and heat transfer in standard batch systems. Accordingly, we have engendered rapid and controlled mass transport through the adoption of microfluidic technologies, ${ }^{54-56}$ which are capable of performing ultrafast kinetic measurements and reaction optimization through the 

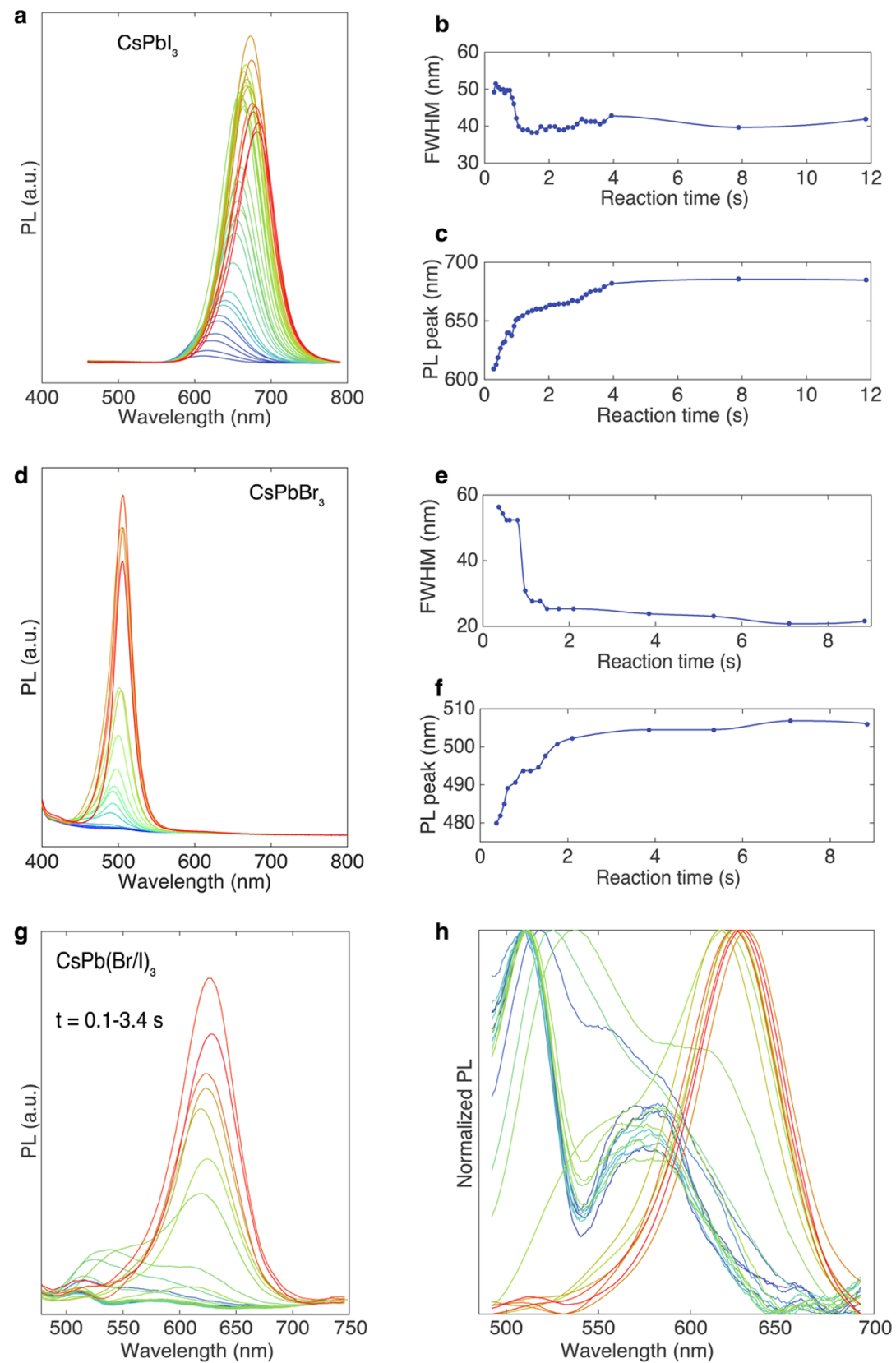

Figure 3. Tuning of the emission characteristics of $\mathrm{CsPbX}_{3}$ perovskite NCs by a systematic variation of the reaction (residence) time from 0.1 to 12 s. $\mathrm{CsPb}_{3}$ : Temporal evolution of (a) the PL emission spectra, (b) fwhm, and (c) PL maximum wavelength at a constant operating temperature of $180{ }^{\circ} \mathrm{C}$ and $R_{1}=4.7$. The red shift in the $\mathrm{CsPbI}_{3}$ band edge emission is between 610 and $685 \mathrm{~nm} . \mathrm{CsPbBr}_{3}$ : Temporal evolution of (d) the PL emission spectra, (e) fwhm, and (f) PL peak wavelength at the synthesis temperature of $160^{\circ} \mathrm{C}$ and $R_{1}=2.2 . \mathrm{CsPb}(\mathrm{Br} / \mathrm{I})_{3}$ : temporal evolution of $(\mathrm{g})$ the PL emission spectra and (h) normalized PL spectra at $180^{\circ} \mathrm{C} ; R_{1}=4.3$ and $R_{2}=1.6$.

use of efficient online PL and absorption measurements. Specifically, we show how the adoption of microfluidic technology yields unique and in situ insights into the early stages of the formation of $\mathrm{CsPbX}_{3} \mathrm{NCs}$ (within the first $0.1-5$ s). We find that NC growth is complete, that is, PL characteristics become constant, within this short period of time for all tested reaction conditions. Furthermore, we demonstrate parametric screening in a manner and on time scales that are inconceivable for batch syntheses. One "synthesis run" in our microfluidic platform requires just a few milliliters of reagents and $1-5 \mathrm{~h}$ of experimental time, yielding information equivalent to $200-1000$ batch reactions, depending upon which parameters are being screened. Unsurprisingly, this translates into time and cost savings of months-to-years and between 10 and $100 \mathrm{~kg}$ of reagents when compared to standard batch-based screening platforms. We exemplify such efficient screening by testing the effects of $\mathrm{Pb} / \mathrm{Cs}$ and $\mathrm{Br} / \mathrm{Cl}$ and $\mathrm{I} / \mathrm{Br}$ molar ratios at various temperatures. We discuss the key observations and conclusions from this multiparametric study and compare the results to conventional batch syntheses. $^{38}$

Experimental Design. Microfluidic reaction systems are adept in transferring mass and energy rapidly, allowing the creation or homogenization of both temperature and reagent gradients on ultrashort time scales. ${ }^{57,58}$ Facile and fast variation of precursor volumetric flow rates and the ability to sequentially 

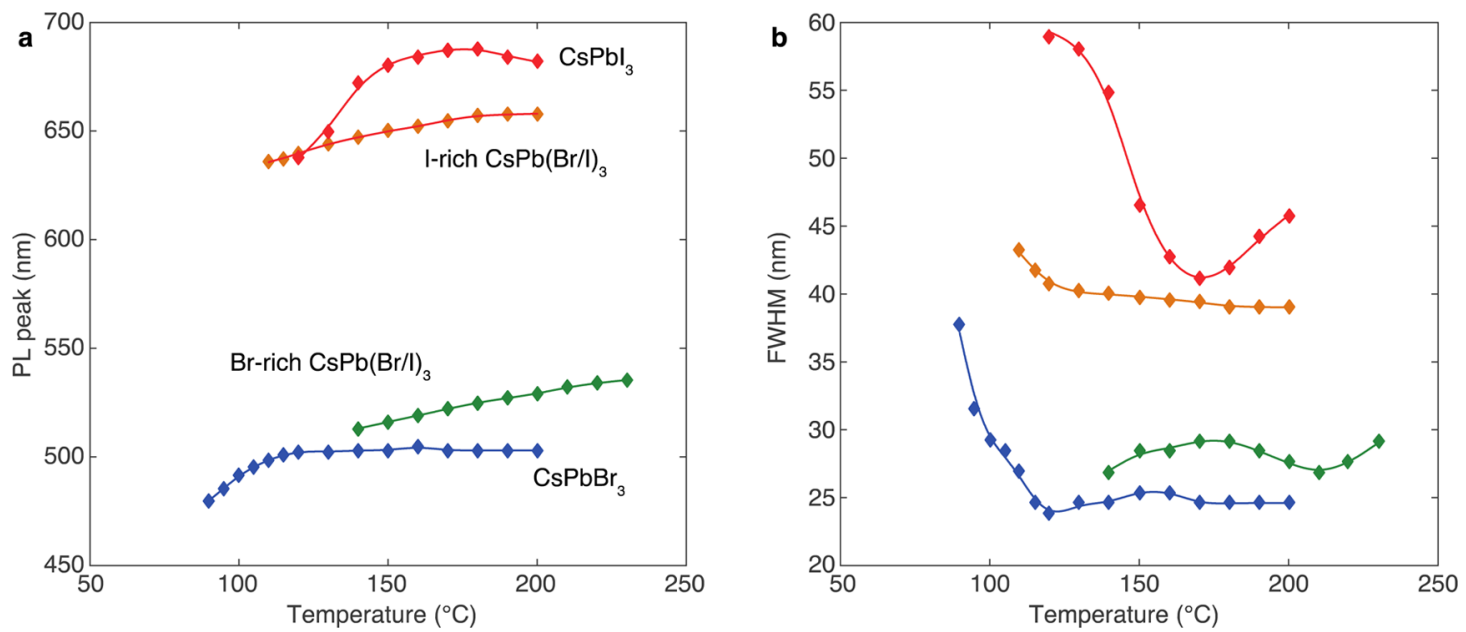

Figure 4. Variation of (a) PL peak wavelength and (b) the PL fwhm as a function of temperature for various halide compositions. CsPbBr $\mathrm{r}_{3}: R_{1}=2.2$, reaction time $-3 \mathrm{~s}$. Br-rich $\mathrm{CsPb}(\mathrm{Br} / \mathrm{I})_{3}: R_{1}=3.6, R_{2}=0.17$, reaction time 5 s. I-rich $\mathrm{CsPb}(\mathrm{Br} / \mathrm{I})_{3}: R_{1}=3.6, R_{2}=6.0$, reaction time $-5 \mathrm{~s}$. CsPbI $: R_{1}$ $=6.5$, reaction time $3 \mathrm{~s}$.

add reagents in a controlled manner enable the production of NCs with varying and complex composition, as well as rapid, accurate, reproducible, and economic screening of parameters. ${ }^{55,56}$ Many researchers have recognized the significance of microfluidics in NC synthesis, demonstrating the synthesis of a large variety of colloidal semiconductors, ${ }^{59-66}$ metals, ${ }^{67-70}$ and metal oxides. ${ }^{64,71,72}$ Recent innovations in real-time spectroscopic analysis ${ }^{63,64,66,73,74}$ and the integration of intelligent algorithm controls ${ }^{65,75,76}$ make microfluidic systems indispensable for high-throughput experimentation. ${ }^{77}$

We designed a rather simple setup for studying the formation of $\mathrm{CsPbX}_{3} \mathrm{NCs}$ (see Figure 1a and associated text in the Supporting Information, including Figures S1-S2), similar to our previous investigation of $\mathrm{PbS} \mathrm{NCs}^{66}$ In this setup, the precursors (loaded into precision syringe pumps) are rapidly mixed using a cross-mixing junction and form droplets that can be rapidly heated to the desired reaction temperature (ca. 100 $\mathrm{ms}$ for the complete temperature ramp; see also Figure S2 for in situ temperature calibration). For mixed halide $\mathrm{CsPb}(\mathrm{X} / \mathrm{Y})_{3}$ systems (where $\mathrm{X}$ and $\mathrm{Y}$ are the two halides), $\mathrm{PbX}_{2}$ and $\mathrm{PbY}_{2}$ precursor solutions are premixed at a $\mathrm{T}$-junction mixer before delivering them into the cross-mixer. With $\mathrm{T}$ - and crossjunctions, the $\mathrm{Pb} / \mathrm{Cs}$ molar ratio $R_{1}$ and halide molar ratios $R_{2}$ $(\mathrm{Br} / \mathrm{Cl}$ or $\mathrm{I} / \mathrm{Br})$ can be adjusted continuously and independently, generating droplets of various compositions. Control over the reaction time is achieved by controlling the residence time of the droplet in the heated zone. Reaction timedependent optical measurements are accomplished by spiral rotation of the heating rod with respect to stationary fiber optics for online measurements of the absorption and emission spectra. Presented reaction times were calculated using the superficial flow rates of the fluids. Control experiment using high-speed imaging of droplets (Figure S3) showed deviation of less than $10 \%$ from the calculated rate. Within the droplets, the complete mixing of precursors occurs in less than $300 \mathrm{~ms}$, as can be seen from the control experiment using a quenching assay of fluorescein/iodide system (Figure S4). This time for mixing is allowed before the droplets enter the heating stage. We recorded early-stage kinetics within $0.1-10 \mathrm{~s}$ from the moment droplets enter the heating stage, as it take up to 100 $\mathrm{ms}$ for heating ramp. Such kinetics was recorded for various reaction temperatures $\left(120-200^{\circ} \mathrm{C}\right)$ and over a broad range of
$R_{1}$ and $R_{2}$ values $\left(R_{1}=0.9-47\right.$ and $\left.R_{2}=0.07-30\right)$. The concentrations of capping ligands (oleic acid and oleylamine) were identical to those used in the previous study, ${ }^{38}$ providing cubic-shaped NCs under all tested $R$-values and temperatures (see representative electron microscopy image in Figure S5).

Fast Early Stage Reaction Kinetics and Possible Mechanism for the Formation of Mixed-Halide NCs. Our main initial conclusion is that the nucleation and growth of $\mathrm{CsPbX}_{3} \mathrm{NCs}$ are fully complete within $1-5 \mathrm{~s}$ at all reaction temperatures and precursor concentrations, indicating that time cannot be used as a "size-tuning" tool in conventional batch syntheses. Besides observing stabilization of PL wavelengths after 3-5 s, we also find that overall PL intensity and optical density of the colloids (at wavelengths of 400-450 nm) do not rise anymore after 3$5 \mathrm{~s}$. Here we exemplify the results for $\mathrm{CsPbI}_{3} \mathrm{NCs}$ (Figure 2). In our previous study, ${ }^{38}$ it was shown that measurement of sizedependent absorption and emission spectra from $\mathrm{CsPbI}_{3} \mathrm{NCs}$ is nearly impossible for batch reactions due to the phasetransition to the wide-gap (yellow) orthorhombic phase, occurring quickly for small NC sizes during NC isolation. On the contrary, with microfluidic platform we can clearly resolve early size-evolution, as shown for the reaction conducted at 180 ${ }^{\circ} \mathrm{C}$ (Figure 2a). Overall, the $\mathrm{CsPbI}_{3}$ absorption maxima evolve between 580 and $670 \mathrm{~nm}$, corresponding to a size-range of $8-$ $12.5 \mathrm{~nm}$ (Figure $2 \mathrm{~b}$, where sizes are estimated from bandgap energies using the effective mass approximation according to ref. $\left.^{38}\right)$. Online PL spectra closely follow the evolution of absorption spectra, also showing a narrowing of the fwhm to $\leq 45 \mathrm{~nm}$ for $\mathrm{CsPbI}_{3}$ (Figure 3a) and $\leq 25 \mathrm{~nm}$ for $\mathrm{CsPbBr}_{3}$ (Figure $3 \mathrm{~b}$ ). In contrast, a very different spectral evolution is observed for mixed-halide systems. Two or more emission peaks are initially observed between 500 and $800 \mathrm{~ms}$; for instance, at 510 and $630 \mathrm{~nm}$ in the $\mathrm{Br} / \mathrm{I}$ system at $180{ }^{\circ} \mathrm{C}$. This can be explained by the formation of small ternary $\mathrm{CsPbBr}_{3}$ and $\mathrm{CsPbI} \mathrm{NCs}_{3}$ at early times, followed by the production of the homogeneous composition at later times with a single narrow $\mathrm{PL}$ band. $\mathrm{CsPbBr}$-related emission eventually disappears, while the growing $\mathrm{NCs}$ of the mixed $\mathrm{CsPb}(\mathrm{Br} / \mathrm{I})_{3}$ attain $\mathrm{PL}$ maxima at $630 \mathrm{~nm}$, noticeably shorter than the $690 \mathrm{~nm}$ representative of pure $\mathrm{CsPbI}_{3}$ under the same growth conditions. Such evolution may invoke aggregation of ternary halide NCs and/or inter-NC anion exchange, previously observed in postsynthetic mixing of 

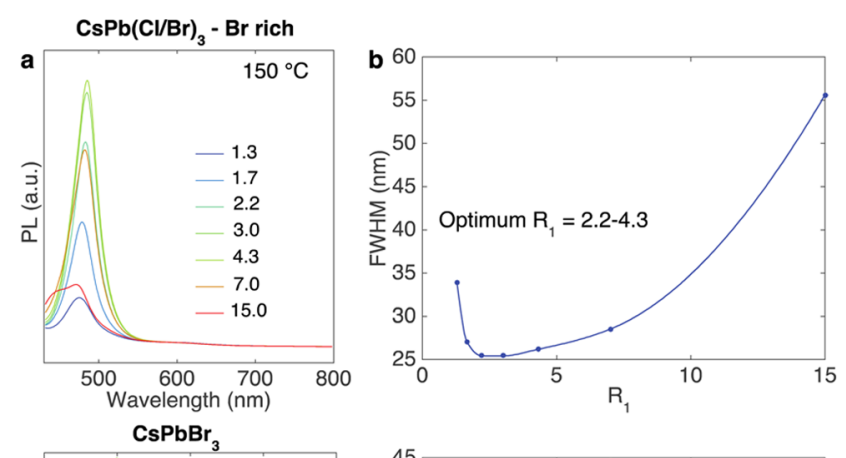

$\mathrm{CsPbX}_{3} \mathrm{NCs}^{39,40}$ Apparently, direct simultaneous coprecipitation of all four ions does not occur! For comparison, a similar scenario had been reported for one-pot syntheses of quaternary metal chalcogenide NCs such as $\mathrm{Cu}_{2} \mathrm{ZnGeSe}_{4},{ }^{78} \mathrm{Cu}_{2} \mathrm{ZnSnS}_{4}{ }^{79}$ and $\mathrm{Cu}_{2-x} \mathrm{ZnSe}_{y} \mathrm{~S}_{1-y}{ }^{80}$ albeit with a much slower progression from the initially formed binary $\mathrm{Cu}$-chalcogenides to ternary and quaternary compositions. Contrary to these chalcogenides, no direct ex situ characterization (i.e., by electron microscopy) of the transient species is possible for the $\mathrm{CsPb}(\mathrm{Br} / \mathrm{I})_{3}$ system.

Tuning of the Optical Properties by Growth Temperature. In the following discussion, the effects of precursor concentrations (through control of $R_{1}$ and $R_{2}$ ) are presented for reaction times of at least $3 \mathrm{~s}$, as this would give optimized reaction conditions that can be realistically attained in a batch reaction in common laboratory glassware. Figure 4 reports the maximal attainable effect of temperature on the most important PL characteristics-the wavelengths of the PL peak and the PL fwhm. Systematic variation of the operating temperature from 90-230 ${ }^{\circ} \mathrm{C}$ leads to a red-shift in the band-edge emission of both ternary $\left(\mathrm{CsPbBr}_{3}\right.$ and $\left.\mathrm{CsPb}_{3}\right)$ and quaternary halide perovskites $\left(\mathrm{CsPb}(\mathrm{Br} / \mathrm{I})_{3} \mathrm{NCs}\right)$. The key message here is that the optimal temperature range for maintaining a satisfactory fwhm is between 130 and $200{ }^{\circ} \mathrm{C}$ for all compositions.

Lead-to-Cesium Molar Ratio (Parameter $R_{1}$ ) and Halide Ratios (Parameter $R_{2}$ ). The mass-balance of the synthesis of $\mathrm{CsPbX}_{3} \mathrm{NCs}$ can be expressed as

$$
2 \text { Cs-oleate }+3 \mathbf{P b X}_{2} \rightarrow 2 \mathbf{C s} \mathbf{P b X _ { 3 }} \mathrm{NCs}+\mathrm{Pb}(\text { oleate })_{2}
$$

$\mathrm{PbX}_{2}$ is the sole source of $\mathrm{X}$-ions and hence one-third of $\mathrm{Pb}$ will always be spent for the formation of lead oleate as byproduct. Accordingly, $R_{1} \geq 1.5$ is generally required to run the synthesis stoichiometrically or under Pb-rich conditions, meaning that in the latter case there is still $\mathrm{PbX}_{2}$ unreacted or combined into mixed lead halide-oleate such as $\mathrm{PbBr}$ (oleate). Such species are presumably also surface-binding. Thus, a different behavior might be expected for Cs-rich conditions $\left(R_{1}\right.$ $<1.5$ ), where the residual, potentially surface active component is Cs-oleate. In fact, reactions conducted at 1.2-1.3 do yield $\mathrm{CsPbX}_{3} \mathrm{NCs}$ but with very poor colloidal stability. A further decrease of $R_{1}$ to 1 corresponds to the formation of hypothetical two-dimensional perovskite $\mathrm{Cs}_{2} \mathrm{PbBr}_{4}$ (or a solution of this compound), thus explaining why we do not observe the formation of $\mathrm{CsPbX}_{3} \mathrm{NCs}$ at $R_{1}<1$. In previous batch investigations, the $R_{1}$ ratio was thus arbitrarily set to 3.76 in all experiments for both single- and mixed-halide systems without any optimization. ${ }^{38}$ We therefore sought to broadly examine whether this $R_{1}$ value is indeed best suited for all halide compositions, $\mathrm{CsPb}(\mathrm{Cl} / \mathrm{Br})_{3}, \mathrm{CsPbBr}_{3}, \mathrm{CsPb}(\mathrm{Br} / \mathrm{I})_{3}$, and $\mathrm{CsPbI}_{3}$. Figure 5 highlights that this $\mathrm{Pb} / \mathrm{Cs}$ molar ratio has a dramatic effect on $\mathrm{CsPbX}_{3} \mathrm{PL}$ intensity and fwhm, as well as on PL peak position. As expected, low values of $R_{1}(\leq 1)$, usually lead to poorly defined PL features. On the other hand, excessively high $R_{1}$ values lead to Cs $\mathrm{PbX}_{3} \mathrm{NCs}$ with broad size distributions and reduced PL intensities. Importantly, the optimal $R_{1}$ range in terms of fwhm and PL intensity is not the same for all halide compositions. Mixed-halide $\mathrm{CsPb}(\mathrm{Br} / \mathrm{I})_{3}$ NCs exhibit a stronger dependence of the optimal $R_{1}$ on the halide ratio $R_{2}$. For instance, the synthesis of $\mathrm{CsPb}(\mathrm{Br} / \mathrm{I})_{3} \mathrm{NCs}$ requires $R_{1}=2.0-2.6$ except for I-rich $\mathrm{CsPb}(\mathrm{Br} / \mathrm{I})_{3}$ emitting beyond $650 \mathrm{~nm}$, where an $R_{1}$ between 3.1 and 4.7 should be used. These results highlight the indispensable role of highthroughput microfluidic screening methods in understanding such complex systems. In general, in an experiment with $N$ 

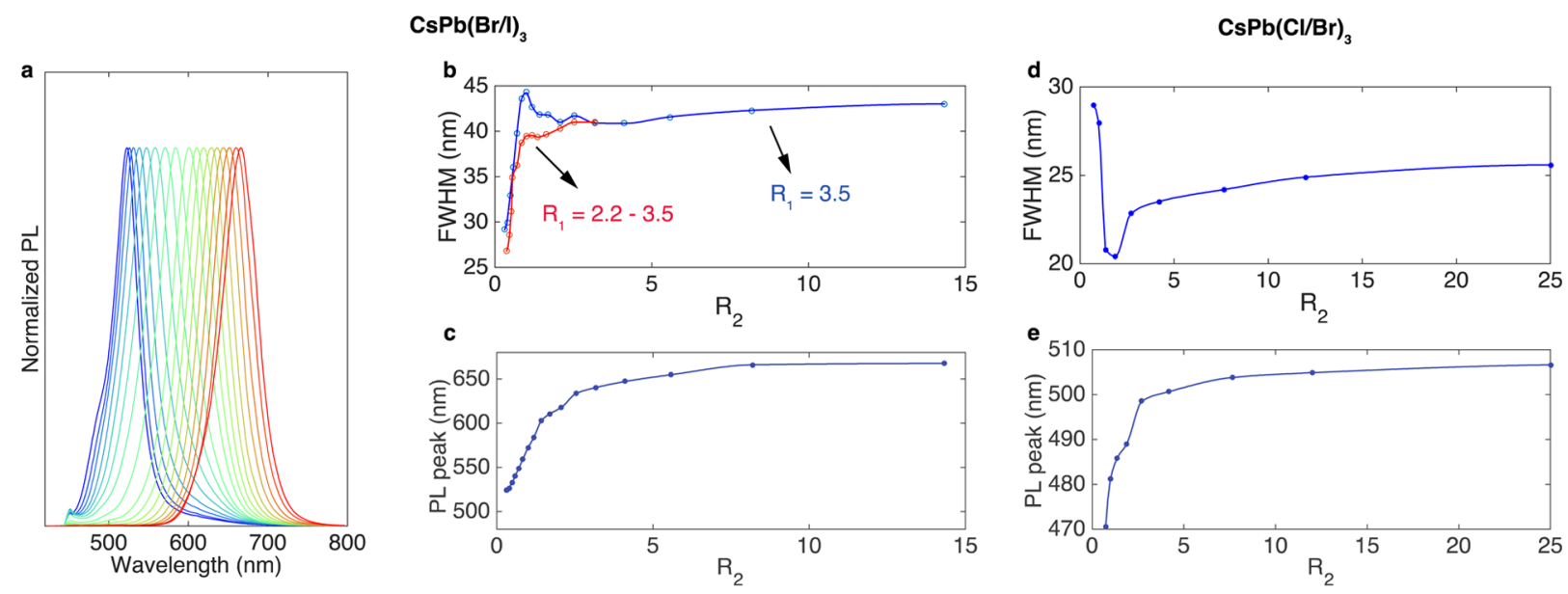

Figure 6. Tuning of the (a) PL emission spectra, (b) PL peak wavelength, and (c) fwhm of $\mathrm{CsPb}(\mathrm{Br} / \mathrm{I})_{3}$ perovskite $\mathrm{NCs}$ by varying the I-to-Br molar ratio $\left(R_{2}=0.03-14.33\right.$ ). Other parameters were $R_{1}=3.5$ (blue curve in panel b) and $R_{1}=2.2-3.5$ (red curve in Figure $6 \mathrm{~b}$ ), $T=160{ }^{\circ} \mathrm{C}$, reaction time $=5 \mathrm{~s}$. Panels $(\mathrm{d})$ and $(\mathrm{e})$ illustrate similar $R_{2}$-dependent study for $\mathrm{CsPb}(\mathrm{Cl} / \mathrm{Br})_{3}$ at $160{ }^{\circ} \mathrm{C}$, reaction time of $5 \mathrm{~s}$, and $R_{1}=3.2$.
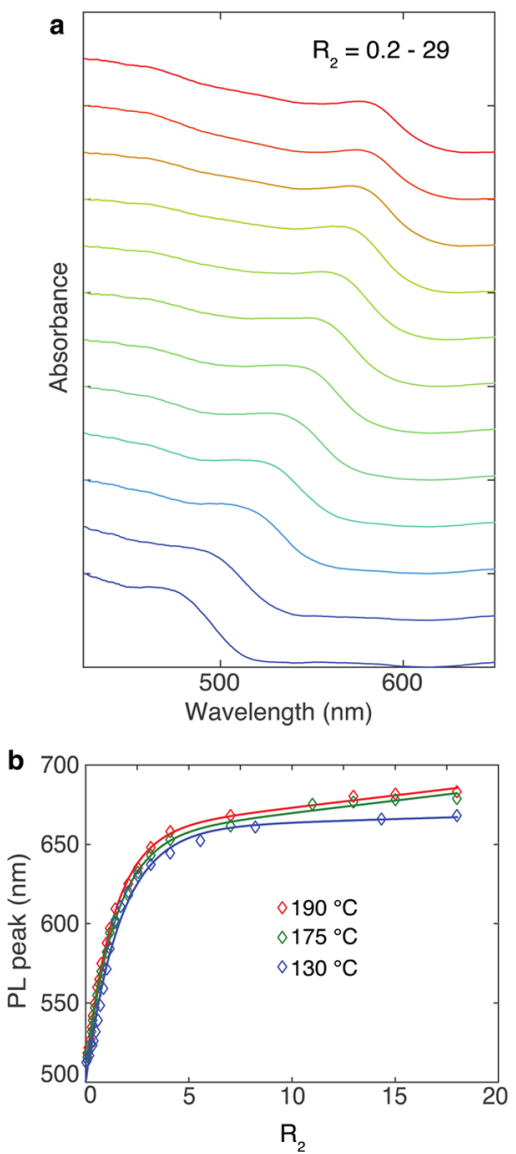

Figure 7. (a) Online absorption spectra of $\mathrm{CsPb}(\mathrm{Br} / \mathrm{I})_{3} \mathrm{NCs}(T=130$ ${ }^{\circ} \mathrm{C}$, reaction time $\left.2 \mathrm{~s}, R_{1}=3.1\right)$ and (b) compilation of PL peak positions at temperatures of $130{ }^{\circ} \mathrm{C}\left(R_{1}=3.1\right), 175{ }^{\circ} \mathrm{C}\left(R_{1}=2.55\right)$, $190{ }^{\circ} \mathrm{C}\left(R_{1}=2.55\right)$ as functions of $R_{2}$.

synthetic variables $\left(R_{1}, R_{2}\right.$, temperature, etc.), each having $M$ levels (defining the selected range of each factor), the overall number of required experimental iterations scales as $M^{N}$. The time needed for these iterations is then given by $M^{N *} t$, where $t$ is the time for one iteration. ${ }^{81}$ Accordingly, fast reactions (small $t$ ) will gain the most from experimentation using microfluidics.
Furthermore, $\mathrm{CsPbX}_{3} \mathrm{NCs}$ are represented, in fact, by five systems (three ternary and two quaternary).

Figure 6 demonstrates how the band edge emission of $\mathrm{Br} / \mathrm{I}$ perovskites can be tuned from 523 to $667 \mathrm{~nm}$ through a continuous variation of $R_{2}$ from 0.3 (for Br-rich NCs) to 14.33 (for I-rich NCs). At the transition from I-rich to Br-rich $\mathrm{CsPb}(\mathrm{Br} / \mathrm{I})_{3} \mathrm{NCs}$, we find a dramatic increase in the fwhm beyond that expected from the conversion of energy to wavelengths $(1 / \lambda$; for example, emission line widths of 100 $\mathrm{meV}$ corresponds to fwhm $=23 \mathrm{~nm}$ at $530 \mathrm{~nm}$ and $\mathrm{fwhm}=25$ at $560 \mathrm{~nm}$ but as high as fwhm $=45$ at $620 \mathrm{~nm}$ ). This can be corrected by readjustment of the $R_{1}$ value into $2.0-2.6$ for $\mathrm{CsPb}(\mathrm{Br} / \mathrm{I})_{3} \mathrm{NCs}$ emitting at $530-590 \mathrm{~nm}$ and $3.0-3.5$ for longer wavelengths (Figure $6 \mathrm{~b}$, red line depicts the effect of optimizing $\left.R_{1}\right)$. Tuning in the blue-green region of 470-510 $\mathrm{nm}$ is accomplished by varying the $\mathrm{Br} / \mathrm{Cl}$ ratio $\left(R_{2}=0.8-10\right.$, Figure 6d,e). Online absorption spectra (Figure 7a) are in accordance with the in situ PL measurements. As expected, temperature has only a subtle effect on the outcome of the synthesis for $T=130-200{ }^{\circ} \mathrm{C}$ (see Figure $7 \mathrm{~b}$ ).

Implications for Conventional Batch Synthesis in ThreeNeck Flasks. Unsurprisingly, we were intrigued by the question whether powerful screening of parameters by the microfluidic platform can directly advance the batch synthesis of the same perovskite NC material. Figure 8 illustrates that indeed conclusions from microfluidic-based screening are directly transferrable to reactions in conventional laboratory glassware (i.e., $25 \mathrm{~mL}$ flasks; see details in the Supporting Information) used in the original development of $\mathrm{CsPbX}_{3} \mathrm{NCs}^{38} \mathrm{We}$ emphasize that simultaneous optimization of interlinked parameters $R_{1}$ and $R_{2}$ at various temperatures in flask-based reactions is essentially impossible due to the prohibitively high number of individual combinations. Thus, far, predominantly $R_{1}=3.76$ can be found in previous reports on the synthesis of $\mathrm{CsPbX}_{3} \mathrm{NCs}^{38-46}$ Herein for the correct and unbiased comparison of various batches, it was critical to avoid the PLnarrowing (size-selective) effect of the isolation and purification procedures, and therefore PL characteristics of the flask-based reactions were recorded from crude solutions diluted by hexane. fwhm values for the flask-synthesized $\mathrm{CsPbBr}_{3} \mathrm{NCs}$ drop from 25.6 to $21.8 \mathrm{~nm}$ when $R_{1}$ is reduced from 3.76 to 1.5-2.00 and the PL spectrum acquires a more symmetric, nearly Gaussian-like shape (Figure 8a). The same effect is seen 


\section{Batch Synthesis in a $25 \mathrm{~mL}$ Flask}
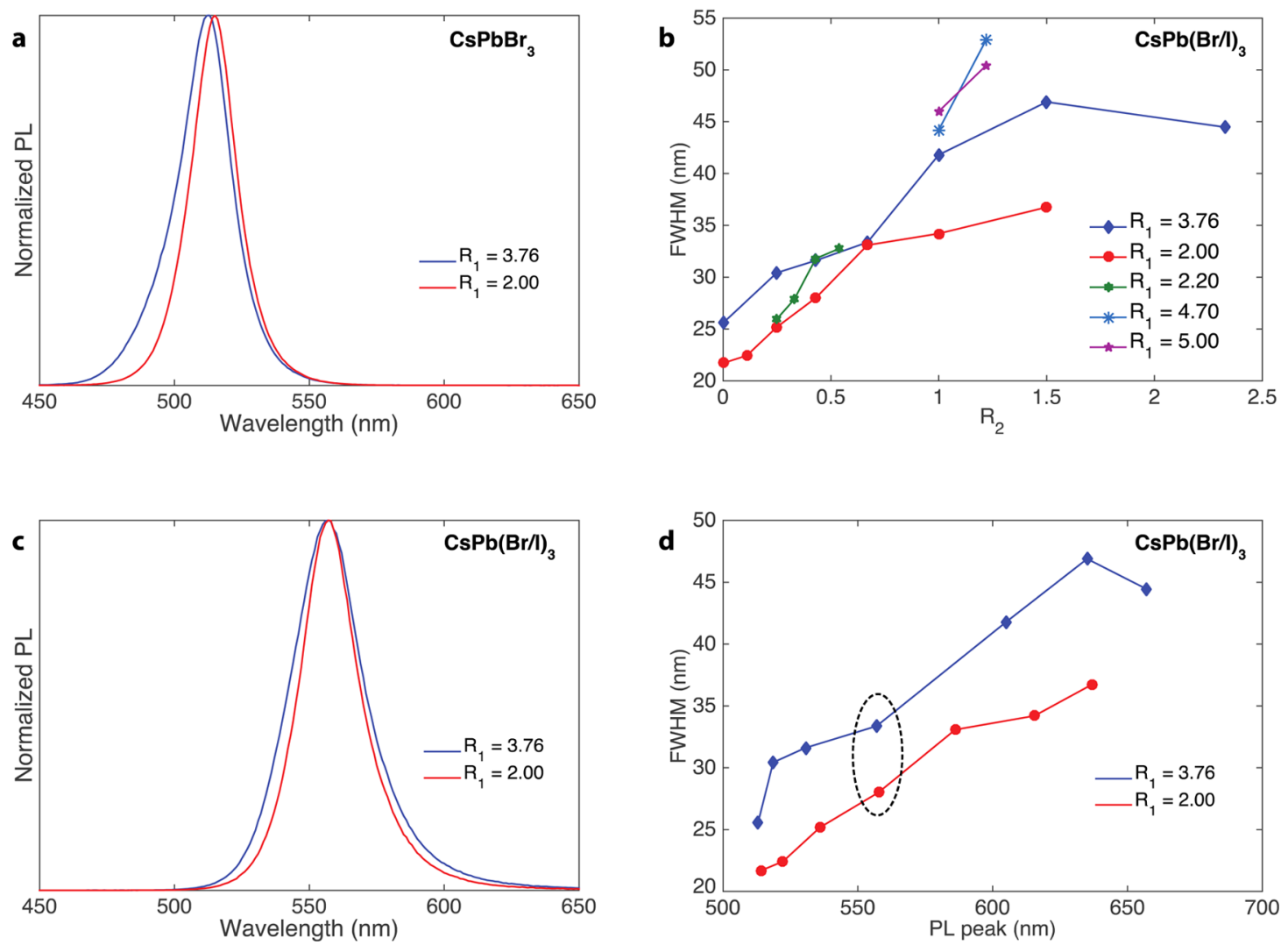

Figure 8. Batch synthesis of $\mathrm{CsPbBr}_{3}$ and $\mathrm{CsPb}(\mathrm{Br} / \mathrm{I})_{3} \mathrm{NCs}$ in a conventional laboratory glassware $\left(25 \mathrm{~mL}\right.$ three-neck flask) using $R_{1}$ values optimized by microfluidic screening. Panels (a) and (c) compare the PL spectra results with $R_{1}=3.76$ and $R_{1}=2$ for $\mathrm{CsPbBr}$ and $\mathrm{CsPb}(\mathrm{Br} / \mathrm{I})_{3} \mathrm{NCs}$ $\left(R_{2}=0.67\right.$ for blue curve and $R_{2}=0.43$ for red curve), respectively. (b) Evolution of fwhm as a function of $R_{2}$ at five different $R_{1}$ molar ratios. (d) fwhm versus PL peak wavelengths for $R_{1}=2.00$ (lower red curve) and $R_{1}=3.76$ (upper blue curve). All experiments were performed at $180{ }^{\circ} \mathrm{C}$. The dashed circle in (d) shows the samples illustrated in (c).

Table 1. Optimized Reaction Parameters for Growing $\mathrm{CsPbX}_{3}$ with Narrow PL FWHM over Broad Range of PL Peak Wavelengths from 470 (blue) to 690 (red)

\begin{tabular}{lcrccc} 
type of $\mathrm{NC}$ & temperature $\left({ }^{\circ} \mathrm{C}\right)$ & \multicolumn{1}{c}{$R_{1}$} & $R_{2}$ & online fwhm $(\mathrm{nm})$ & $\mathrm{PL}$ \\
$\mathrm{CsPb}(\mathrm{Br} / \mathrm{Cl})_{3}$ & $130-180$ & $2.2-4.3$ & $1.5-10$ & $20-25$ & $470-500$ \\
$\mathrm{CsPbBr}$ & $140-200$ & $1-2.4$ & & $20-25$ & $480-510$ \\
$\mathrm{CsPb}(\mathrm{Br} / \mathrm{I})_{3}$ & $150-220$ & $2.0-2.6$ & $0.1-1$ & $25-35$ & $510-580$ \\
& $150-220$ & $3.2-4.5$ & $1.2-15$ & $35-45$ & $580-660$ \\
$\mathrm{CsPb}_{3}$ & $150-200$ & $3.2-7.5$ & & $38-45$ & $650-690$
\end{tabular}

also in the flask-syntheses of $\mathrm{CsPb}(\mathrm{Br} / \mathrm{I})_{3} \mathrm{NCs}$ at various $R_{2}$ values (Figure $8 \mathrm{~b}$; results for 22 flask-based syntheses). Qualitatively, microfluidics-optimized parameters yield similar results in conventional batch glassware. Because PL peak wavelengths at a given $R_{2}$ are often slightly different for different $R_{1}$ values, Figure $8 \mathrm{c}$ reports two selected samples with exactly the same PL peak wavelengths and shows a clear narrowing of fwhm with reducing $R_{1}$ (Figure $8 \mathrm{c}$ ). Likewise, Figure $8 \mathrm{~d}$ replots the data for $R_{1}=3.76$ and $R_{1}=2.00$ in fwhm versus wavelengths coordinates, covering the whole green-tored spectral range $(514-650 \mathrm{~nm})$.

Conclusions. In summary, we have demonstrated that microfluidic systems are unique tools for studying and optimizing the synthesis parameters of the colloidal synthesis of $\mathrm{CsPbX}_{3} \mathrm{NCs}$, leading to production of materials with superior PL characteristics. Table 1 presents the refined parameters that we recommend also for the batch syntheses of these NCs. In this regard, we note that the temperature in our microfluidic platform is typically between 1 and $10{ }^{\circ} \mathrm{C}$ higher than the nominal "injection/growth" temperatures reported for batch syntheses. The actual temperature in the batch synthesis during the first several seconds is lower due to the effect of the injection of cold Cs-oleate precursor. In addition, microfluidic systems have been shown to successfully unearth unique insights into the early stages of nucleation and growth within the initial $0.1-5 \mathrm{~s}$, simply not accessible in batch investigations, where this time scale covers the period during which the mixing of precursors and heat exchange occur. Specifically in regard to $\mathrm{CsPbX}_{3} \mathrm{NCs}$, a fast pathway "precursors" $\rightarrow \mathrm{CsPbBr}_{3} \mathrm{NCs}+\mathrm{CsPbI}_{3} \mathrm{NCs} \rightarrow \mathrm{CsPb}(\mathrm{Br} / \mathrm{I})_{3}$ NCs is observed, presumably accomplished via fast inter-NC anion exchange or fusion of NCs in the last stage. The overall conclusions from the study of early-stage kinetics and the complete screening of parametric space (here $T, R_{1}, R_{2}$ ) are that 
growth times are fast under all conditions ( $\leq 3 \mathrm{~s}$ ), optimal temperatures are between 140 and $200{ }^{\circ} \mathrm{C}$, and emission wavelengths can be accurately and reproducibly controlled only via control of halide composition, whereas simultaneous adjustments of $R_{1}$ and $R_{2}$ are needed to minimize fwhm.

\section{ASSOCIATED CONTENT}

\section{S Supporting Information}

The Supporting Information is available free of charge on the ACS Publications website at DOI: 10.1021/acs.nanolett.5b04981.

Synthesis details and optical characterization techniques. (PDF)

\section{AUTHOR INFORMATION}

\section{Corresponding Authors}

*E-mail: andrew.demello@chem.ethz.ch.

*E-mail: mvkovalenko@ethz.ch.

\section{Notes}

The authors declare no competing financial interest.

\section{ACKNOWLEDGMENTS}

The work was supported by the Swiss National Science Foundation (Grant 200021_143638).

\section{REFERENCES}

(1) Grätzel, M. Nat. Mater. 2014, 13, 838-842.

(2) Green, M. A.; Ho-Baillie, A.; Snaith, H. J. Nat. Photonics 2014, 8, 506-514.

(3) Park, N.-G. J. Phys. Chem. Lett. 2013, 4, 2423-2429.

(4) Zhou, H.; Chen, Q.; Li, G.; Luo, S.; Song, T.-B.; Duan, H.-S.; Hong, Z.; You, J.; Liu, Y.; Yang, Y. Science 2014, 345, 542-546.

(5) Chung, I.; Lee, B.; He, J.; Chang, R. P. H.; Kanatzidis, M. G. Nature 2012, 485, 486-489.

(6) Stranks, S. D.; Eperon, G. E.; Grancini, G.; Menelaou, C.; Alcocer, M. J. P.; Leijtens, T.; Herz, L. M.; Petrozza, A.; Snaith, H. J. Science 2013, 342, 341-344.

(7) Xing, G.; Mathews, N.; Sun, S.; Lim, S. S.; Lam, Y. M.; Graetzel, M.; Mhaisalkar, S.; Sum, T. C. Science 2013, 342, 344-347.

(8) Nie, W.; Tsai, H.; Asadpour, R.; Blancon, J.-C.; Neukirch, A. J.; Gupta, G.; Crochet, J. J.; Chhowalla, M.; Tretiak, S.; Alam, M. A.; Wang, H. L.; Mohite, A. D. Science 2015, 347, 522-525.

(9) Dong, Q.; Fang, Y.; Shao, Y.; Mulligan, P.; Qiu, J.; Cao, L.; Huang, J. Science 2015, 347, 967-970.

(10) Shi, D.; Adinolfi, V.; Comin, R.; Yuan, M.; Alarousu, E.; Buin, A.; Chen, Y.; Hoogland, S.; Rothenberger, A.; Katsiev, K.; Losovyj, Y.; Zhang, X.; Dowben, P. A.; Mohammed, O. F.; Sargent, E. H.; Bakr, O. M. Science 2015, 347, 519-522.

(11) Saidaminov, M. I.; Adinolfi, V.; Comin, R.; Abdelhady, A. L.; Peng, W.; Dursun, I.; Yuan, M.; Hoogland, S.; Sargent, E. H.; Bakr, O. M. Nat. Commun. 2015, 6, 8724.

(12) Walters, G.; Sutherland, B. R.; Hoogland, S.; Shi, D.; Comin, R.; Sellan, D. P.; Bakr, O. M.; Sargent, E. H. ACS Nano 2015, 9, 93409346.

(13) Jeon, N. J.; Noh, J. H.; Yang, W. S.; Kim, Y. C.; Ryu, S.; Seo, J.; Seok, S. I. Nature 2015, 517, 476-480.

(14) National Renewable Energy Laboratory (NREL). Best ResearchCell Efficiencies; http://www.nrel.gov/ncpv/images/efficiency_chart. jpg (accessed January, 2016).

(15) Zhu, H.; Fu, Y.; Meng, F.; Wu, X.; Gong, Z.; Ding, Q.; Gustafsson, M. V.; Trinh, M. T.; Jin, S.; Zhu, X.-Y. Nat. Mater. 2015, $14,636-642$.

(16) Dou, L.; Yang, Y. M.; You, J.; Hong, Z.; Chang, W.-H.; Li, G.; Yang, Y. Nat. Commun. 2014, 5, 5404.
(17) Sutherland, B. R.; Johnston, A. K.; Ip, A. H.; Xu, J.; Adinolfi, V.; Kanjanaboos, P.; Sargent, E. H. ACS Photonics 2015, 2, 1117-1123.

(18) Maculan, G.; Sheikh, A. D.; Abdelhady, A. L.; Saidaminov, M. I.; Hague, M. A.; Murali, B.; Alarousu, E.; Mohammed, O. F.; Wu, T.; Bakr, O. M. J. Phys. Chem. Lett. 2015, 6, 3781-3786.

(19) Guo, Y.; Liu, C.; Tanaka, H.; Nakamura, E. J. Phys. Chem. Lett. 2015, 6, 535-539.

(20) Yakunin, S.; Sytnyk, M.; Kriegner, D.; Shrestha, S.; Richter, M.; Matt, G. J.; Azimi, H.; Brabec, C. J.; Stangl, J.; Kovalenko, M. V.; Heiss, W. Nat. Photonics 2015, 9, 444-449.

(21) Tan, Z.-K.; Moghaddam, R. S.; Lai, M. L.; Docampo, P.; Higler, R.; Deschler, F.; Price, M.; Sadhanala, A.; Pazos, L. M.; Credgington, D.; Hanusch, F.; Bein, T.; Snaith, H. J.; Friend, R. H. Nat. Nanotechnol. 2014, 9, 687-692.

(22) Sutherland, B. R.; Hoogland, S.; Adachi, M. M.; Wong, C. T. O.; Sargent, E. H. ACS Nano 2014, 8, 10947-10952.

(23) Xing, G.; Mathews, N.; Lim, S. S.; Yantara, N.; Liu, X.; Sabba, D.; Grätzel, M.; Mhaisalkar, S.; Sum, T. C. Nat. Mater. 2014, 13, 476480.

(24) Zhang, Q.; Ha, S. T.; Liu, X.; Sum, T. C.; Xiong, Q. Nano Lett. 2014, 14, 5995-6001.

(25) Deschler, F.; Price, M.; Pathak, S.; Klintberg, L. E.; Jarausch, D. D.; Higler, R.; Huettner, S.; Leijtens, T.; Stranks, S. D.; Snaith, H. J.; Atatüre, M.; Phillips, R. T.; Friend, R. H. J. Phys. Chem. Lett. 2014, 5, $1421-1426$

(26) Zhang, F.; Zhong, H.; Chen, C.; Wu, X.-G.; Hu, X.; Huang, H.; Han, J.; Zou, B.; Dong, Y. ACS Nano 2015, 9, 4533-4542.

(27) Tyagi, P.; Arveson, S. M.; Tisdale, W. A. J. Phys. Chem. Lett. 2015, 6, 1911-1916.

(28) Huang, H.; Susha, A. S.; Kershaw, S. V.; Hung, T. F.; Rogach, A. L. Adv. Sci. 2015, 2, 1500194.

(29) Li, G.; Tan, Z.-K.; Di, D.; Lai, M. L.; Jiang, L.; Lim, J. H.-W.; Friend, R. H.; Greenham, N. C. Nano Lett. 2015, 15, 2640-2644.

(30) Wong, A. B.; Lai, M.; Eaton, S. W.; Yu, Y.; Lin, E.; Dou, L.; Fu, A.; Yang, P. Nano Lett. 2015, 15, 5519-5524.

(31) Schmidt, L. C.; Pertegas, A.; Gonzalez-Carrero, S.; Malinkiewicz, O.; Agouram, S.; Minguez Espallargas, G.; Bolink, H. J.; Galian, R. E.; Perez-Prieto, J. J. Am. Chem. Soc. 2014, 136, 850-853.

(32) Jang, D. M.; Park, K.; Kim, D. H.; Park, J.; Shojaei, F.; Kang, H. S.; Ahn, J.-P.; Lee, J. W.; Song, J. K. Nano Lett. 2015, 15, 5191-5199.

(33) Chen, Z.; Li, H.; Tang, Y.; Huang, X.; Ho, D.; Lee, C.-S. Mater. Res. Express 2014, 1, 015034.

(34) Ha, S. T.; Liu, X.; Zhang, Q.; Giovanni, D.; Sum, T. C.; Xiong Q. Adv. Opt. Mater. 2014, 2, 838-844.

(35) Zhu, F.; Men, L.; Guo, Y.; Zhu, Q.; Bhattacharjee, U.; Goodwin, P. M.; Petrich, J. W.; Smith, E. A.; Vela, J. ACS Nano 2015, 9, 29482959.

(36) Gonzalez-Carrero, S.; Galian, R. E.; Perez-Prieto, J. J. Mater. Chem. A 2015, 3, 9187-9193.

(37) Hassan, Y.; Song, Y.; Pensack, R. D.; Abdelrahman, A. I.; Kobayashi, Y.; Winnik, M. A.; Scholes, G. D. Adv. Mater. 2016, 28, 566-573.

(38) Protesescu, L.; Yakunin, S.; Bodnarchuk, M. I.; Krieg, F.; Caputo, R.; Hendon, C. H.; Yang, R. X.; Walsh, A.; Kovalenko, M. V. Nano Lett. 2015, 15, 3692-3696.

(39) Nedelcu, G.; Protesescu, L.; Yakunin, S.; Bodnarchuk, M. I.; Grotevent, M. J.; Kovalenko, M. V. Nano Lett. 2015, 15, 5635-5640.

(40) Akkerman, Q. A.; D’Innocenzo, V.; Accornero, S.; Scarpellini, A.; Petrozza, A.; Prato, M.; Manna, L. J. Am. Chem. Soc. 2015, 137, 10276-10281.

(41) Zhang, D.; Eaton, S. W.; Yu, Y.; Dou, L.; Yang, P. J. Am. Chem. Soc. 2015, 137, 9230-9233.

(42) Park, Y.-S.; Guo, S.; Makarov, N. S.; Klimov, V. I. ACS Nano 2015, 9, 10386-10393.

(43) Wang, Y.; Li, X.; Song, J.; Xiao, L.; Zeng, H.; Sun, H. Adv. Mater. 2015, 27, 7101-7108.

(44) Song, J.; Li, J.; Li, X.; Xu, L.; Dong, Y.; Zeng, H. Adv. Mater. 2015, 27, 7162-7167. 
(45) Yakunin, S.; Protesescu, L.; Krieg, F.; Bodnarchuk, M. I.; Nedelcu, G.; Humer, M.; De Luca, G.; Fiebig, M.; Heiss, W.; Kovalenko, M. V. Nat. Commun. 2015, 6, 8056.

(46) Swarnkar, A.; Chulliyil, R.; Ravi, V. K.; Irfanullah, M.; Chowdhury, A.; Nag, A. Angew. Chem., Int. Ed. 2015, 54, 1542415428 .

(47) Wang, Y.; Leck, K. S.; Van Duong Ta; Chen, R.; Nalla, V.; Gao, Y.; He, T.; Demir, H. V.; Sun, H. Adv. Mater. 2015, 27, 169-175.

(48) Dang, C.; Lee, J.; Breen, C.; Steckel, J. S.; Coe-Sullivan, S.; Nurmikko, A. Nat. Nanotechnol. 2012, 7, 335-339.

(49) Dang, C.; Nurmikko, A. MRS Bull. 2013, 38, 737-742.

(50) Chen, O.; Zhao, J.; Chauhan, V. P.; Cui, J.; Wong, C.; Harris, D. K.; Wei, H.; Han, H.-S.; Fukumura, D.; Jain, R. K.; Bawendi, M. G. Nat. Mater. 2013, 12, 445-451.

(51) Carbone, L.; Nobile, C.; De Giorgi, M.; Sala, F. D.; Morello, G.; Pompa, P.; Hytch, M.; Snoeck, E.; Fiore, A.; Franchini, I. R.; Nadasan, M.; Silvestre, A. F.; Chiodo, L.; Kudera, S.; Cingolani, R.; Krahne, R.; Manna, L. Nano Lett. 2007, 7, 2942-2950.

(52) Mahler, B.; Nadal, B.; Bouet, C.; Patriarche, G.; Dubertret, B. J. Am. Chem. Soc. 2012, 134, 18591-18598.

(53) Brandt, R. E.; Stevanovic, V.; Ginley, D. S.; Buonassisi, T. MRS Commun. 2015, 5, 265-275.

(54) Kovalenko, M. V.; Manna, L.; Cabot, A.; Hens, Z.; Talapin, D. V.; Kagan, C. R.; Klimov, V. I.; Rogach, A. L.; Reiss, P.; Milliron, D. J.; Guyot-Sionnest, P.; Konstantatos, G.; Parak, W. J.; Hyeon, T.; Korgel, B. A.; Murray, C. B.; Heiss, W. ACS Nano 2015, 9, 1012-1057.

(55) Niu, G.; Ruditskiy, A.; Vara, M.; Xia, Y. Chem. Soc. Rev. 2015, 44, 5806-5820.

(56) Phillips, T. W.; Lignos, I. G.; Maceiczyk, R. M.; deMello, A. J.; deMello, J. C. Lab Chip 2014, 14, 3172-3180.

(57) Elvira, K. S.; i Solvas, X. C.; Wootton, R. C. R.; deMello, A. J. Nat. Chem. 2013, 5, 905-915.

(58) Teh, S.-Y.; Lin, R.; Hung, L.-H.; Lee, A. P. Lab Chip 2008, 8, 198-220.

(59) Edel, J. B.; Fortt, R.; deMello, J. C.; deMello, A. J. Chem. Commun. 2002, 1136-1137.

(60) Chan, E. M.; Alivisatos, A. P.; Mathies, R. A. J. Am. Chem. Soc. 2005, 127, 13854-13861.

(61) Baek, J.; Allen, P. M.; Bawendi, M. G.; Jensen, K. F. Angew. Chem., Int. Ed. 2011, 50, 627-630.

(62) Kwon, B.-H.; Lee, K. G.; Park, T. J.; Kim, H.; Lee, T. J.; Lee, S. J.; Jeon, D. Y. Small 2012, 8, 3257-3262.

(63) Nightingale, A. M.; Krishnadasan, S. H.; Berhanu, D.; Niu, X.; Drury, C.; McIntyre, R.; Valsami-Jones, E.; deMello, J. C. Lab Chip 2011, 11, 1221-1227.

(64) Lignos, I.; Protesescu, L.; Stavrakis, S.; Piveteau, L.; Speirs, M. J.; Loi, M. A.; Kovalenko, M. V.; deMello, A. J. Chem. Mater. 2014, 26, $2975-2982$.

(65) Maceiczyk, R. M.; deMello, A. J. J. Phys. Chem. C 2014, 118, 20026-20033.

(66) Lignos, I.; Stavrakis, S.; Kilaj, A.; deMello, A. J. Small 2015, 11, 4009-4017.

(67) Sebastian Cabeza, V.; Kuhn, S.; Kulkarni, A. A.; Jensen, K. F. Langmuir 2012, 28, 7007-7013.

(68) Khan, S. A.; Duraiswamy, S. Lab Chip 2012, 12, 1807-1812.

(69) Duraiswamy, S.; Khan, S. A. Small 2009, 5, 2828-2834.

(70) Zhang, L.; Niu, G.; Lu, N.; Wang, J.; Tong, L.; Wang, L.; Kim, M. J.; Xia, Y. Nano Lett. 2014, 14, 6626-6631.

(71) Khan, S. A.; Günther, A.; Schmidt, M. A.; Jensen, K. F. Langmuir 2004, 20, 8604-8611.

(72) Erdem, E. Y.; Cheng, J. C.; Doyle, F. M.; Pisano, A. P. Small 2014, 10, 1076-1080.

(73) Leonard, J.; Dumas, N.; Causse, J.-P.; Maillot, S.; Giannakopoulou, N.; Barre, S.; Uhring, W. Lab Chip 2014, 14, 4338-4343.

(74) Abolhasani, M.; Coley, C. W.; Xie, L.; Chen, O.; Bawendi, M. G.; Jensen, K. F. Chem. Mater. 2015, 27, 6131-6138.

(75) Krishnadasan, S.; Brown, R. J. C.; deMello, A. J.; deMello, J. C. Lab Chip 2007, 7, 1434-1441.
(76) Toyota, A.; Nakamura, H.; Ozono, H.; Yamashita, K.; Uehara, M.; Maeda, H. J. Phys. Chem. C 2010, 114, 7527-7534.

(77) Maceiczyk, R. M.; Lignos, I. G.; deMello, A. J. Curr. Opin. Chem. Eng. 2015, 8, 29-35.

(78) Ibáñez, M.; Zamani, R.; LaLonde, A.; Cadavid, D.; Li, W.; Shavel, A.; Arbiol, J.; Morante, J. R.; Gorsse, S.; Snyder, G. J.; Cabot, A. J. Am. Chem. Soc. 2012, 134, 4060-4063.

(79) Shavel, A.; Cadavid, D.; Ibáñez, M.; Carrete, A.; Cabot, A. J. Am. Chem. Soc. 2012, 134, 1438-1441.

(80) Lesnyak, V.; George, C.; Genovese, A.; Prato, M.; Casu, A.; Ayyappan, S.; Scarpellini, A.; Manna, L. ACS Nano 2014, 8, 84078418.

(81) Martínez, E. C. Ind. Eng. Chem. Res. 2005, 44, 8796-8805. 